\title{
Uji antagonis Pseudomonas fluorescens untuk mengendalikaan penyakit bercak ungu pada tanaman bawang merah
}

\author{
Antagonism test of Pseudomonas fluorescens for control purple blotch disease on shallot \\ Andri Laksono $^{1 *}$, Joko Gagung Sunaryono ${ }^{2}$, Rika Despita ${ }^{3}$ \\ ${ }^{1}$ Politeknik Pembangunan Pertanian Malang \\ ${ }^{2}$ Politeknik Pembangunan Pertanian Malang \\ ${ }^{3}$ Politeknik Pembangunan Pertanian Malang \\ *Email Korespondensi: andrilaksono02@gmail.com
}

Diterima: 18 November 2020 / Disetuji: 31 Maret 2021

\begin{abstract}
Purple blotch disease on shallot caused by Alternaria porri can result in a percentage of yield loss reaching $57 \%$. The continued use of chemical fungicides has a negative impact on humans and the environment. One of the controls safe and environmentally friendly is biological control based on antagonistic microorganisms. This research aims to find out the best concentration of the biological agent Pseudomonas fluorescens to control purple blotch disease in bauji varieties. This study used a randomized block design (RBD) with 6 treatments and the number of repetitions 4 times. The treatments included: P1 (control), P2 (concentration $20 \mathrm{ml} / \mathrm{l}$ ), P3 (concentration $40 \mathrm{ml} / \mathrm{l}$ ), P4 (concentration $60 \mathrm{ml} / \mathrm{l}), P 5$ (concentration $80 \mathrm{ml} / \mathrm{l}$ ), P6 $($ concentration $100 \mathrm{ml} / \mathrm{l}$ ). l). Data obtained were analyzed using analysis of variance, if there is a significant difference then proceed with the Duncan test at the $5 \%$ level. The results showed that the Pseudomonas fluorescens concentration $100 \mathrm{ml} / \mathrm{l}$ was able to effectively control purple blotch disease with the worst attack intensity of $22.47 \%$, besides that Pseudomonas fluorescens was able to extend the incubation disease period and produce a tuber wet weight which was significantly different compared to the control.
\end{abstract}

Key words: purple blotch disease, Pseudomonas fluorescens, shallots.

\section{ABSTRAK}

Penyakit bercak ungu pada tanaman bawang merah yang disebabkan oleh cendawan Alternaria porri dapat mengakibatkan persentase kehilangan hasil panen mencapai 57\%. Penggunaan fungisida kimia secara terus menerus memiliki dampak negatif bagi manusia dan lingkungan. Salah satu pengendalian yang aman dan ramah lingkungan yaitu pengendalian hayati dengan mikroorganisme antagonis. Penelitian ini bertujuan untuk mengetahui konsentrasi terbaik agen hayati Pseudomonas fluorescens untuk mengendalikan penyakit bercak ungu pada tanaman bawang merah varietas bauji. Penelitian ini menggunakan Rancangan Acak Kelompok (RAK) dengan 6 perlakuan dan jumlah ulangan sebanyak 4 kali. Perlakuan tersebut meliputi : P1(kontrol), P2 (konsentrasi $20 \mathrm{ml} / \mathrm{l}$ ), P3 (konsentrasi $40 \mathrm{ml} / \mathrm{l}$ ), P4 (konsentrasi $60 \mathrm{ml} / \mathrm{l}$ ), P5 (konsentrasi $80 \mathrm{ml} / \mathrm{l})$, P6 (konsentrasi $100 \mathrm{ml} / \mathrm{l}$ ). Data yang diperoleh kemudian dianalisis menggunakan analisis varian, dan uji lanjut menggunakan Duncan taraf 5\%. Hasil penelitian menunjukkan bahwa konsentrasi Pseudomonas fluorescens $100 \mathrm{ml} / \mathrm{l}$ mampu mengendalikan penyakit bercak ungu dengan intensitas serangan sebesar 22,47\%, selain itu Pseudomonas fluorescens mampu memperpanjang periode inkubasi penyakit dan menghasilkan bobot basah umbi yang berbeda nyata dibandingkan dengan kontrol.

Kata kunci : penyakit bercak ungu, Pseudomonas fluorescens, bawang merah.

\section{PENDAHULUAN}

Bawang merah merupakan salah satu komoditas hortikultura yang memiliki prospek pasar cukup bagus, memiliki nilai ekomoni yang tinggi dan penting bagi kehidupan masyarakat. Kabupaten Nganjuk merupakan salah satu wilayah di Jawa Timur yang memproduksi bawang merah varietas bauji. Varietas ini menjadi unggulan petani bawang merah di sana karena memiliki umbi yang besar dan umur panen yang cukup singkat yaitu 60 hst, produksi bawang merah di Kabupaten Nganjuk tahun 2018 mencapai 1,524,084 kwintal dan menguasai lebih dari sepertiga kebutuhan bawang merah di Jawa Timur atau sekitar 41,52\% (BPS Jawa Timur, 2018).

Dengan kondisi cuaca yang tidak menentu salah satu penyakit penting yang harus di waspadai dalam usaha tani budidaya bawang merah adalah bercak ungu yang disebabkan oleh cendawan Alternaria porri. penggunaaan fungisida 
kimia secara terus menerus mengakibatkan dampak negatif bagi manusia dan lingkungan, sehingga perlu adanya upaya pengendalian hayati terhadap serangan cendawan patogen Alternaria porri. Pseudomonas fluorescens merupakan microorganisme yang ramah lingkungan dan sudah terbukti ampuh dalam mengendalikan dan mengurangi intensitas serangan cendawan Alternaria porri pada tanaman bawang merah (Soesanto, 2010). Walaupun demikian, hingga saat ini konsentrasi terbaik agen hayati Pseudomonas fluorescens untuk mengendalikan serangan penyakit bercak ungu belum diketahui.

Tujuan penelitian ini adalah untuk mengetahui konsentrasi terbaik larutan agen hayati Pseudomonas fluorescens yang dapat memberikan pengaruh terbaik terhadap serangan penyakit bercak ungu. Sehingga dari penelitian yang di lakukan diperoleh informasi mengenai konsentrasi terbaik larutan agen hayati Pseudomonas fluorescens yang dapat di rekomendasikan kepada petani untuk mengendalikan serangan cendawan patogen Alternaria porri penyebab penyakit bercak ungu pada tanaman bawang merah.

\section{BAHAN DAN METODE}

Penelitian ini dilaksanakan pada bulan Maret s/d Juni 2020 di Desa Sonobekel Kecamatan Tanjunganom Kabupaten Nganjuk. bahan yang digunakan adalah: tanah, air, pupuk kompos, pupuk NPK, SP 36, bibit bawang merah varietas bauji, Polybag diameter $12,5 \mathrm{~cm}$, agen hayati Pseudomonas fluorescens dan isolat patogen Alternaria porri.

Penelitian menggunakan Rancangan Acak Kelompok (RAK) dengan 6 perlakuan konsentrasi agen hayati yang berbeda yaitu P1 sebagai Kontrol, P2 : 20ml/1, P3 : 40ml/1, P4 : 60ml/1, P5 : 80ml/1 dan P6 : 100ml/1. Masing-masing perlakuan berdasarkan per hitungan menggunakan rumus Hanafiah, (1994) diperloeh ulangan sebanyak 4 kali, sehingga diperoleh 24 satuan percobaan.

\section{Persiapan Media Tanam}

Media tanam yang digunakan adalah tanah katel sebesar 1.820 gram dan pupuk kompos sebesar 180 gram perpolybag kemudian di campur. Campuran tanah katel dan pupuk kandang di masukkan ke dalam plastik tahan panas berukuran $5 \mathrm{Kg}$. kemudian disterilisasi menggunakan sterilitator bag log jamur dengan suhu $121^{\circ} \mathrm{C}$ selama 12 jam (Pujiati, 2017).

\section{Inokulasi Cendawan Patogen Alternaria porri}

Inokulasi cendawan patogen Alternaria porri dilakukan pada 3 hari sebelum tanam melalui inokulasi buatan. Dilakukan dengan cara di kocorkan sebanyak 50ml ke dalam media tanam dan dilakukan pada saat sore hari setelah pukul 16.00 wib.

\section{Penanaman}

Penanaman dilakukan dengan cara memasukkan umbi bawang merah kedalam media tanam dengan gerakan memutar. Kemudian setiap polybag diisi dengan satu bibit bawang merah (Azizah, 2019).

\section{Inokulasi Agen Hayati Pseudomonas fluorescens}

Inokulasi biakan cair agen hayati dilakukan saat tanam (H0), setiap minggu setelah tanam sampai dengan minggu ke 7 menjelang panen. Aplikasi dilakukan sesuai konsentrasi yang telah ditentukan dan disemprotkan pada seluruh bagian tamanan. Setiap tanaman disemprot $\pm 20 \mathrm{ml}$.

\section{Perawatan dan Pemeliharaan Tanaman}

Perawatan tanaman bawang merah dilakukan seperti budidaya bawang merah pada umumnya. Meliputi pemupukan susulan, penyiangan dan penyiraman. Pada proses penyiraman dilakukan 2 kali sehari yaitu pagi pada pukul 06.00 wib dan sore pada pukul 16.00 wib, jika ada hujan disiang hari, maka tetap dilakukan penyiraman untuk membersihkan sisa air hujan dan sisa tanah yang menempel karena dapat membuat permukaan daun terluka sehingga mempermudah cendawan menginfeksi (Suwandi, 2014).

Pada saat tanaman sudah berumur 6 minggu setelah tanam penyiraman cukup dilakukan satu kali sehari pada pagi atau sore hari. Pemupukan susulan pertama dilakukan saat tanaman berumur 14 hst menggunakan pupuk NPK 20 gram pertanaman, dan pupuk Sp 36 sebanyak 30 gram pertanaman. kemudian pemupukan susulan ke 2 dilakukan pada saat tanaman umur 35 hst menggunakan pupuk NPK 20 gram pertanaman, dan pupuk Sp 36 sebanyak 30 gram pertanaman. Setelah itu dilakukan penyiraman dengan air bersih.

Penyiangan dilakukan sesuai dengan kondisi pertumbuhan gulma di lapangan, berkisar antara 1-2 kali pengendalian, sebelum pemberian pupuk susulan. Gulma dikendalikan secara manual (Suwandi, 2014).

\section{Pemanenan}

Pemanenan dilaksanakan pada saat tanaman bawang merah berumur 60 hst dengan ciri $60 \%$ leher batang sudah lunak, tanaman rebah, dan daun menguning (Suwandi, 2014). Cara pemanenan adalah dengan mencabut umbi bawang merah sampai keakarnya, kemudian dibersihkan daun, akar dan sisa tanah yang terangkat.

\section{Parameter Pengamatan}

1. Periode Inkubasi

Periode inkubasi diamati sejak inokulasi cendawan patogen Alternaria porri sampai awal munculnya gejala penyakit bercak ungu pertama pada tanaman bawang merah. Pengamatan periode inkubasi dilakukan setiap hari sampai tanaman tampak bergejala.

2. Intensitas Serangan Penyakit

Intensitas serangan diamati dengan menghitung jumlah daun yang terserang kemudian dibagi dengan total 
jumlah daun tanaman. Pengamatan dilaksanakan pada saat tanaman berumur 21hst, 28hst, 35 hst, 42 hst dan 49 hst. Cara menghitung intensitas serangang menggunakan rumus (Nurhayati, 2011):

Keterangan:

$$
\text { IS }=\mathbf{n} / \mathbf{N} \times \mathbf{1 0 0}
$$

IS : Intensitas Serangan Penyakit (\%)

$\mathrm{n}:$ Jumlah daun yang terserang

$\mathrm{N}$ : Total jumlah daun tanaman

3. Bobot Umbi Basah

Bobot basah umbi bawang merah diukur menggunakan timbangan digital. Cara pengukuran dengan menimbang umbi yang dihasilkan setiap tanaman.

\section{Analisis Data}

Data hasil pengamatan dianalisis dengan uji $\mathrm{F}$ atau Analisis Of Variance (ANOVA) dengan taraf nyata 5\% (Sugiyono, 2017). Apabila terdapat perbedaan nyata maka dilakukan uji lanjut menggunakan uji Duncan pada taraf 5\%.

\section{HASIL DAN PEMBAHASAN}

\section{Periode Inkubasi}

Bedasarkan analisis statistik menunjukkan hasil yang berbeda nyata antara berbagai konsentrasi agen hayati terhadap periode inkubasi penyakit bercak ungu pada setiap perlakuan. Perlakuan 1 yaitu kontrol menunjukkan rata-rata periode inkubasi tercepat di bandingkan dengan perlakuan lainnya.

Berdasarkan hasil pengamatan, gejala awal penyakit bercak ungu pada tanaman bawang merah mulai terlihat pada hari ke 10 hingga hari ke 30 setelah tanam. Periode inkubasi tercepat terdapat pada perlakuan 1 (kontrol), hal tersebut diduga karena pada perlakuan 1 tidak diaplikasikan agen hayati antagonis sehingga cendawan patogen Alternaria porri yang diinokulasikan dapat berkembang tanpa adanya agen hayati yang memperkuat ketahanan jaringan tanaman. Selain itu kesesuaian patogen dengan tanaman bawang merah menyebabkan gejala muncul lebih awal. Hal tersebut sesuai dengan pendapat Santoso, (2007) yang menyatakan bahwa cepat munculnya gejala patogen yang diinokulasikan karena tingkat agresifnya patogen dalam menimbulkan penyakit serta tidak adanya penghambatan pertumbuhan dan perkembangan patogen. Kondisi tersebut didukung dengan kondisi iklim mikro yang lembab sehingga cendawan patogen mudah tumbuh dan berkembang.

Kemudian pada tanaman bawang merah yang memiliki sistem perakaran dangkal dan kasar akan mudah mendapat gangguan penyakit apabila memiliki sistem perakaran yang lemah.

Periode inkubasi terlama terdapat pada perlakuan 6 dengan konsentrasi Pseudomonas fluorescens $100 \mathrm{ml} / \mathrm{l}$ hal tersebut diduga karena semakin banyak jumlah koloni agen hayati antagonis yang bersimbiosis dengan akar akan membuat akar dan jaringan tanaman lebih tahan. perakaran yang kuat akan mendukung tanaman dapat tumbuh lebih baik dan sehat. Tanaman yang sehat akan lebih sulit diserangan oleh patogen. Sesuai dengan penelitian yang dilaksanakan oleh Swastiningrum, (2015) bahwa agen hayati Pseudomonas fluorescens dapat mempersempit lebar bukaan stomata pada tebu, hal ini semakin memperkuat potensi agen hayati Pseudomonas fluorescens sebagai agensi pengendali hayati untuk patogen yang penetrasinya melalui stomata seperti Alternaria porri.

\section{Intensitas Serangan Penyakit}

Terdapat perbedaan yang nyata antara perlakuan terhadap intensitas serangan penyakit (Tabel 2). Perlakuan 1 yaitu kontrol menunjukkan rata-rata intensitas serangan tertinggi pada setiap waktu pengamatan dan berbeda nyata dengan perlakuan lainnya.

intensitas serangan terbesar terdapat pada perlakuan 1 (kontrol) diduga karena pada $\mathrm{P} 1$ hanya diinokulasi cendawan patogen Alternaria porri tanpa agen hayati Pseudomonas fluorescens sehingga jamur penyebab penyakit bercak ungu dapat berkembang dan menginfeksi jaringan tanaman. Menurut Pawana et al, (2019) tanaman yang diberi PGPR cenderung lebih tahan terhadap patogem. Alternaria porri penyebab bercak ungu merupakan cendawan yang bersifat nekrotrofik, yaitu cendawan yang hidup dan berkembang pada sisa-sisa tanaman yang mati, dan apabila kondisi tanaman lemah, karena kekurangan unsur hara maupun cekaman lainnya maka dapat menyerang dan menimbulkan kerugian bagi tanaman. Sedangkan agen hayati Pseudomonas fluorescens mempunyai sifat Plant Growth-Promoting Rhizobacteria (PGPR) yang salah satu fungsinya adalah pemacu pertumbuhan tanaman (Soesanto, 2011).

\section{Bobot Umbi Basah}

Berdasarkan analisis secara statistik (Tebel 3) menunjukkan hasil yang berbeda nyata antara berbagai konsentrasi agen hayati dengan bobot umbi basah bawang merah pada setiap perlakuan. Perlakuan 6 yaitu konsentrasi agen hayati $100 \mathrm{ml} / \mathrm{l}$ menunjukkan rata-rata bobot umbi basah terberat dan berbeda nyata dengan perlakuan lain.

Pada hasil analisis menunjukkan bahwa perlakuan 6 berbeda nyata dengan P1 (kontrol). Hal ini mengindikasikan bahwa pemberian agen hayati Pseudomonas fluorescens dengan konsentrasi $100 \mathrm{ml} / 1$ dan diaplikasikan setiap 7 hari sekali secara tidak langsung dapat meningkatkan produktivitas tanaman bawang merah.

Pengaruh langsung agen hayati Pseudomonas fluorescens berdasarkan kemampuannya untuk menyediakan dan membantu penyerapan berbagai unsur hara di dalam tanah serta mensintesis dan mengubah konsentrasi fitohormon pemacu pertumbuhan tanaman (ZPT). Sedangkan secara tidak langsung berkaitan dengan kemampuan menekan aktivitas penyakit dengan menghasilkan berbagai senyawa atau metabolit seperti antibiotik (Kloepper, J, W 1993). Hal tersebut diduga bahwa penyemprotan 7 hari sekali dapat menekan intensitas serangan secara signifikan, dengan berkurangnya intensitas serangan tersebut maka semakin 
sedikit permukaan daun yang terluka sehingga mengurangi hambatan fotosintesis bagi tanaman.

Tanaman bawang merah yang memiliki sistem perakaan yang terlindungi akibat dikolonisasi oleh agen hayati Pseudomonas fluorescens mampu menyerap unsur hara lebih banyak sehingga produktivitas tanaman akan ikut naik. Bakteri tersebut hidup secara berkoloni dan mengelilingi akar tanaman. Agen hayati tersebut memberikan keuntungan dalam proses fisiologi tanaman dan pertumbuhannya serta biologis bagi tanah. Sesuai dengan pendapat Agrios (2005) yang menyatakan bahwa patogen dapat menganggu fotosintesis yang mengakibatkan klorosis, nekrosis, terhambatnya pertumbuhan dan berkurangnya produktivitas.

Tabel 1. Rata-rata periode inkubasi serangan penyakit bercak ungu pada bawang merah dengan aplikasi berbagai konsentrasi Pseudomonas fluorescens.

\begin{tabular}{lcl}
\hline Perlakuan & Rata Rata (hst) \\
\hline $\mathrm{P} 1=$ kontrol & 10,13 a \\
$\mathrm{P} 2=20 \mathrm{ml} / \mathrm{l}$ & $14,75 \mathrm{~b}$ \\
$\mathrm{P} 3=40 \mathrm{ml} / 1$ & $19,63 \quad \mathrm{c}$ \\
$\mathrm{P} 4=60 \mathrm{ml} / \mathrm{l}$ & $21,00 \mathrm{~cd}$ \\
$\mathrm{P} 5=80 \mathrm{ml} / 1$ & $25,63 \mathrm{e}$ \\
$\mathrm{P} 6=100 \mathrm{ml} / \mathrm{l}$ & $30,00 \mathrm{f}$ \\
\hline $\mathrm{KK}$ & \multicolumn{2}{c}{13,01} \\
\hline
\end{tabular}

Keterangan : Data yang diikuti oleh huruf yang sama pada kolom yang sama menunjukkan tidak berbeda nyata pada uji Duncan taraf 5\%
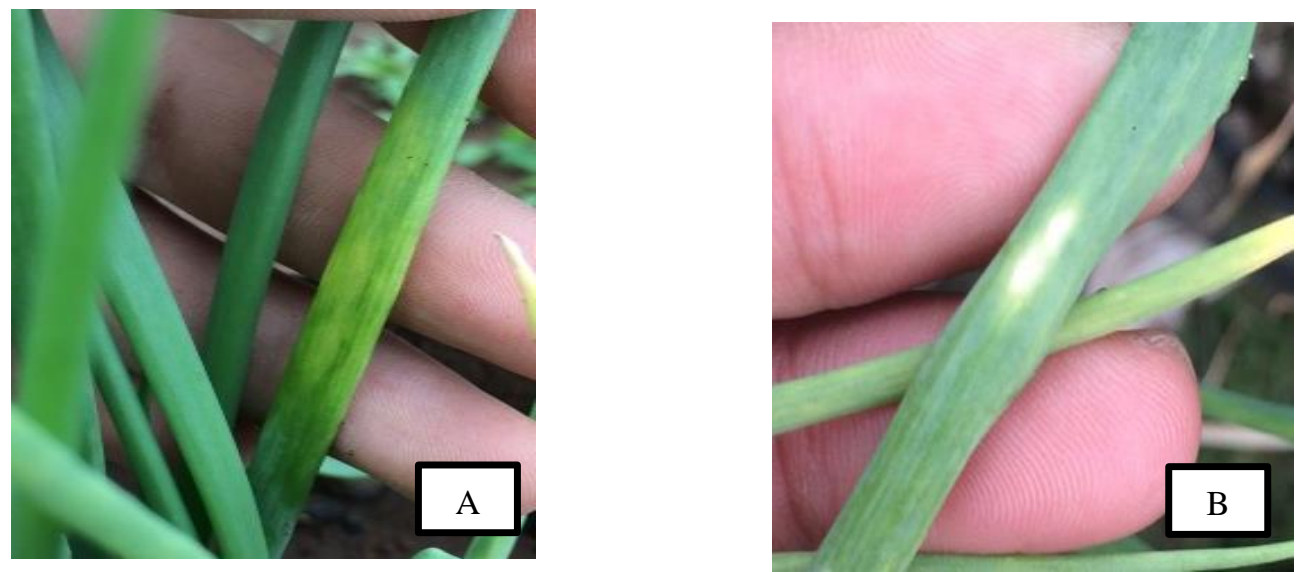

Gambar 1. Gejala Penyakit Bercak Ungu (a) bercak kecil berjumlah banyak dan tidak beraturan, berwarna putih, serta melengkung kedalam (b) Bercak nekrotik tersebut kemudian melebar, disertai dengan bagian tengah berwarna cokelat dengan tepi berwarna kuning kecoklatan

Tabel 2. Rata-rata intensitas serangan penyakit bercak ungu pada bawang merah dengan aplikasi berbagai konsentrasi Pseudomonas fluorescens.

\begin{tabular}{lccccc}
\hline Perlakuan & \multicolumn{4}{c}{ Intensitas Serangan (\%) Pada pengamatan Ke } \\
\cline { 2 - 6 } & $21 \mathrm{hst}$ & $28 \mathrm{hst}$ & $35 \mathrm{hst}$ & $42 \mathrm{hst}$ & $49 \mathrm{hst}$ \\
\hline P1 & $34,73 \mathrm{f}$ & $39,24 \mathrm{f}$ & $49,69 \mathrm{f}$ & $63,24 \mathrm{f}$ & $78,40 \mathrm{f}$ \\
P2 & $26,43 \mathrm{de}$ & $28,18 \mathrm{be}$ & $35,20 \mathrm{be}$ & $31,31 \mathrm{ce}$ & $25,42 \mathrm{ce}$ \\
P3 & $23,44 \mathrm{~cd}$ & $26,46 \mathrm{ad}$ & $30,88 \mathrm{ad}$ & $19,39 \mathrm{ac}$ & $12,86 \mathrm{ab}$ \\
P4 & $18,47 \mathrm{bc}$ & $22,79 \mathrm{ac}$ & $27,83 \mathrm{ac}$ & $21,26 \mathrm{ad}$ & $17,54 \mathrm{ad}$ \\
P5 & $12,14 \mathrm{~b}$ & $22,61 \mathrm{ab}$ & $26,05 \mathrm{ab}$ & $18,71 \mathrm{ab}$ & $16,71 \mathrm{ac}$ \\
& & & $2,47 \mathrm{a}$ & $14,55 \mathrm{a}$ & $11,42 \mathrm{a}$ \\
P6 & $2,08 \mathrm{a}$ & $19,15 \mathrm{a}$ & 27,55 & 20,97 \\
\hline KK & 26,20 & 19,15 & 23,36 & 27 \\
\hline
\end{tabular}

Keterangan : Data yang diikuti oleh huruf yang sama pada kolom yang samamenunjukkan tidak berbeda nyata pada uji Duncan taraf $5 \%$. 
Tabel 3. Rata-rata hasil umbi pada bawang merah dengan aplikasi berbagai konsentrasi Pseudomonas fluorescens.

\begin{tabular}{|c|c|}
\hline Perlakuan & Rata-rata (gram) \\
\hline $\mathrm{P} 1=$ kontrol & 10,13 a \\
\hline $\mathrm{P} 2=20 \mathrm{ml} / \mathrm{l}$ & $37,63 \quad b$ \\
\hline $\mathrm{P} 3=40 \mathrm{ml} / \mathrm{l}$ & $52,75 \quad \mathrm{c}$ \\
\hline $\mathrm{P} 4=60 \mathrm{ml} / \mathrm{l}$ & $67,25 \mathrm{~d}$ \\
\hline $\mathrm{P} 5=80 \mathrm{ml} / \mathrm{l}$ & 72,00 de \\
\hline $\mathrm{P} 6=100 \mathrm{ml} / \mathrm{l}$ & $81,88 \mathrm{f}$ \\
\hline KK & 10,64 \\
\hline
\end{tabular}

Pada perlakuan 2, 3, 4 dan 5 menghasilkan bobot umbi basah yang lebih ringan dibandingkan dengan perlakuan 6 . Diduga bahwa konsentrasi Pseudomonas fluorescens yang digunakan masih kurang, sehingga tidak mampu menekan serangan cendawan patogen Alternaria porri dengan maksimal. Sesuai dengan penelitian Ika Wati dan Despita (2019) bahwa Pseudomonas fluorescens yang merupakan bakteri Plant Growth Promoting Rhizobacteria (PGPR) secara tidak langsung memiliki kemampuan menyediakan nutrisi penting tanaman seperti nitrogen, fospat, sulfur dan kalium serta zat besi dan ion. Ketersediaan unsur hara bagi tanaman mempengaruhi jumlah daun pada tanaman bawang merah sehingga mempengaruhi jumlah anakan atau jumlah umbi bawang merah. Menurut Despita, et al (2017) Penambahan beberapa daun akan memacu penambahan umbi tanaman bawang merah sehingga dapat meningkatkan hasil.

\section{KESIMPULAN}

Pengaplikasian agen hayati Pseudomonas fluorescens dengan konsentrasi $100 \mathrm{ml} / \mathrm{l}$ air. mampu menekan dan menurunkan intensitas serangan penyakit bercak ungu dengan rata-rata periode inkubasi terlama yaitu 30 hst dan persentase intensitas serangan terendah sebesar 2,08\%. Ratarata berat umbi basah bawang merah pada perlakuan terbaik (perlakuan $6=$ konsentrasi agen hayati $100 \mathrm{ml} / \mathrm{l}$ ) yaitu sebesar 82 gram/tanaman.

\section{SARAN}

Perlu dilakukan penelitian lebih lanjut terhadap penggunan agen hayati Pseudomonas fluorescens untuk mengendalikan serangan penyakit pada bawang merah dengan cara melakukan penelitian serupa pada varietas, konsentrasi larutan dan lokasi yang berbeda.

\section{DAFTAR PUSTAKA}

Agrios, G. N. (2005). Plant diseases caused by nematodes. Plant pathology, 4, 565-597.

Azizah. (2020). Uji Antagonis Agensi Hayati Dalam Pengendalian Penyakit Layu Fusarium Pada Tanaman Bawang Merah Secara In Vitro Dan In Vivo
Di Kecamatan Pajarakan Kabupaten Probolinggo. Laporan Tugas Akhir, Politeknik Pembangunan Pertanian Malang.

Badan Pusat Statistik Jawa Timur., (2018). Analisis Data Bawang Merah Jawa Timur. Jawa Timur : Badan Pusat Statistik Jawa Timur.

Despita, R, \& Budianto. (2017). Pertumbuhan dan Hasil Bawang Merah Akibat Perlakuan Pupuk Organik dan Hayati.

Hanafiah, A. S. (1994). Mikroorganisme Pelarut P Sebagai Suatu Alternatif Pengganti Fungsi Pupuk TSP dan Kapur dalam Upaya Mengatasi Ketersediaan Fosfat bagi Tanaman. seminar hasil pertanian RATA XV. BKS-PTN Barat banda Lampung.

Ika Wati, Yuli, \& Rika D. (2019). Peningkatan Pertumbuhan dan Produksi Tanaman Bawang Merah (Allium ascalonicum L) dengan Aplikasi Rhizobakteri. Prosiding The 3th Satreps Conference LIPI 2018.

Creswell, J. W. (2014). Research Design, Terjemahan Edisi Ketiga. Pustaka Pelajar. Yogyakarta.

Kloepper, J. W. (1992). Plant growth-promoting rhizobacteria as biological control agents. Soil microbial ecology: applications in agricultural and environmental management., 255-274.

Nurhayati. (2011). Penggunaan Jamur dan Agen hayati Dalam Pengendalian Penyakit tanaman Secara Hayati yang Ramah Lingkungan. Prosiding Semirata Bidang Ilmu-ilmu Pertanian BKS-PTN Wilayah Barat. ISBN: 978-979-8389-18-4.

Pawana, G., Djunaedy, A., \& Khoiri, S. (2019). Respon Bibit Tebu Akibat Komposisi Media Tanam yang Diaplikasikan Formulasi Dobel Inokulan Pseudomonad Pendarflor dan Azospirillum. Agrovigor: Jurnal Agroekoteknologi, 12(1), 39-46. 
Pujiati. (2017). Budidaya Bawang Merah Pada Lahan Sempit. Program Studi Pendidikan Biologi Fakultas Keguruan dan Ilmu Pendidikan Universitas PGRI. Madiun.

Santoso, S. E., Soesanto, L., \& Haryanto, T. A. D. (2007). Penekanan hayati penyakit moler pada bawang merah dengan Trichoderma harzianum, Trichoderma koningii, dan Pseudomonas fluorescens P60. Jurnal Hama dan Penyakit Tumbuhan Tropika, 7(1).

Semangun, H. (1996). Pengantar ilmu penyakit tumbuhan. Gadjah Mada University Press. Yogyakarta.

Soesanto, L., Mugiastuti, E., Rahayuniati, R. F., \& Manan, A.
(2011). Uji Lapangan Formula Cair Pseudomonas fluorescens P60 terhadap Layu Fusarium pada Tanaman Tomat. Jurnal Perlindungan Tanaman Indonesia, 17(2), 82-90.

Sugiyono, D. P. (2017). Statistika untuk Penelitian (28th editi). Bandung: Alfabeta.

Suwandi. (2014). Budidaya Bawang Merah Diluar Musim. Badan Penelitian dan Pengembangan Pertanian. Kementerian Pertanian.

Swastiningrum, A. (2015). Mekanisme Jamur Mikoriza arbuskular dalam menekan perkembangan penyakit pada bibit tebu. Universitas Gadjah Mada. 